\title{
Model equations of fluorescent lamps on the high frequency operation (2)
}

\author{
Muhammad TOLA*, Kimihiko NAKAMURA** and Hiroshi B⿸尸 ${ }^{* *}$
}

\begin{abstract}
Model equations of fluorescent lamps were investigated as well on the high frequency operation. In the analysis of operating of the fluorescent lamp, the model equation of equivalent conductance of lamp on the high frequency is needed to performed. The model equations are estimated by the error-rate between the experimental waveform and the simulation waveform on the various operating frequencies. Any comparisons of differential model equations, model constants, and other components are discussed by relating characteristics of the fluorescent lamps on the high frequency operation. By using the delay time for the lamp voltage and lamp current, the error-rate values are improved. In each category of model equations, the most significant model equations are discussed. Some of the model equations are most suitable to simulate the characteristics of fluorescent lamp, therefore the ability of the model equations on the high frequency operation are increased.
\end{abstract}

\section{Introduction}

The majority of fluorescent lamps which are used today are operated with the commercial frequency operation of $50 \mathrm{~Hz}$ or $60 \mathrm{~Hz}$ with electromagnetics type ballast. At the present time, the fluorescent lamps are the main light sources for indoors, because have some excellent features and suitable for indoor lighting. They have high efficiency, good color rendering, little generation of heat, and so on. But there are disadvantage, that is spending much time to start, being cause of the influence of the ambient temperature. These disadvantage are improved by using the semiconductor ballast in practic. However, it is difficult to design and analize the operating circuit since the fluorescent lamps have nonlinear and negative resistance characteristics. Therefore, the model equations are expected to express the electrical characteristics of lamps precisely on the high frequency operation. Thus, it is expected to apply the model equation of equivalent conductance to the fluorescent lamps on the high frequency.

* Division of Material Science, The Graduate School of Science and Technology, Kobe University, Rokkodai, Kobe 657, Japan.

** Department of Electronic, Faculty of Engineering, Kobe University, Rokkodai, Kobe 657, Japan

The paper presentated at Kansai Regional Joint Convention of Electrical Engineering of Japan, November 10, 1984.
In the recent years have been written and issued which are deal the application of semiconductor ballast circuit in the fluorescent lamps. The reasons for applying solid state components for ballasting are, the ballast can be made much smaller, the watt losses will be lower, the lamp efficiency will be higher, and the luminous ripple will be very slight. In view of the above mention are advantageous for the fluorescent lamps on the high frequency operation. It might be thought that this would be done quite often, however the economics of the system depend very much on the circumstances.

The most important function of model equation is to provide the available model equations of fluorescent lamps, which are operated in the high frequency. Therefore, the purpose of this paper has prompted a need for increase understanding the fluorescent lamps which are operated on the high frequency. It is shown, that the optimum constants of equivalent conductance of model equation can be determined easily by smoothing pulsation waveforms and applying the simplex method. In this paper, the characteristics of fluorescent lamp FL40 and the comparison of each model equations at the high frequency operation are discussed.

\section{Model equations of fluorescent lamp}

The work of this paper is described to aim the 
analysis of model equations of fluorescent lamps relating on the high frequency. The model equations have been developed and available to describe the characteristics of lamp. The performance of electrical characteristics of fluorescent lamps are necessary to consider the components inside the lamp such as the electrons, the positive ions, etc. The differential model equations which are possessed many of desired characteristics have been suggested by $(1) \sim(3)$, while the formulations were developed by the suggestion of Francis's postulations.

The differential equation of electron density $n$ is proposed to the equivalent conductance $g$, then we express the model equation as follow

$$
\frac{d g}{d t}=P(i, v)-Q(g), \ldots \ldots \ldots \ldots
$$

where $P(i, v)$ is the increase term, and $Q(g)$ is the decrease term. In the differential equation has two important sections, first is the increase term which is a function of the lamp voltage $v$ and the lamp current $i$, second is the decrease term which is a function of the electron density $n$ or equivalent conductance $g$.

Before we make decision to fit a differential model equation of equivalent conductance of fluorescent lamp, we consider the lamp voltage wave and the lamp current wave in half cycle. Then, the wave turn over for the same shape but opposite sign (positive and negative form). However the equivalent conductance $g=i / v$ must be identical for half cycle. As this mention for one period $T$, the differential equation is express as

$$
\frac{d g}{d t}(t+T / 2)=\frac{d g}{d t}(t) \ldots \ldots \ldots \ldots \ldots
$$

If we consider the identity of $d n / d t$ for the first half cycle with time $t$ positive and the next half cycle for time $t$ negative, the voltage and current waves repeat with period $T$, then (1) becomes

$$
\begin{aligned}
\frac{d g}{d t} & =P[i(t+T / 2), v(t+T / 2)]-Q[g(t+T / 2)] \\
& =P[i(t), v(t)]-Q[g(t)], \ldots \ldots(3)
\end{aligned}
$$

where; $i(t+T / 2)=-i(t)$

$$
\begin{aligned}
& v(t+T / 2)=-v(t) \ldots \ldots \ldots \ldots(4) \\
& g(t+T / 2)=+g(t) .
\end{aligned}
$$

From (3) and (4) we obtained as

$$
\begin{aligned}
& P[-i(t),-v(t)]-Q[g(t)]=P[i(t), v(t)] \\
& \quad-Q[g(t)], \ldots \ldots \ldots \ldots \ldots \ldots(5)
\end{aligned}
$$

or, $P(i, v)=P(-i,-v) \ldots \ldots \ldots \ldots(6)$

In $P(i, v)$, we suggested that there are some components of $i$ as $i, i^{2}, i^{4}, \ldots$, etc., components of $v$ as $v, v^{2}, v^{4}, \ldots$, etc., and the components of both of $i$ and $v$ as $i v, i^{2} v$, iv ${ }^{3}, \ldots$, etc. From this matter, we can assume the differential equation as

$$
P(i, v)=A i^{2}+B i v+C v^{2}, \ldots \ldots \ldots
$$

where $A, B, C$ are the constants.

Then we consider the decrease term $Q(g)$ in Equation (1). It is considered that the equivalent conductance $g$ decreases by the disappearance of the electron, which causes by the volume recombination, the diffusion and et al. The volume recombination and the diffusion in the plasma are generally described as Equation (8), (9) respectively.

$$
\begin{aligned}
& d n / d t=-K^{\prime} n^{2}, \ldots \ldots \ldots \ldots \ldots \ldots \\
& d n / d t=-K j n, \ldots \ldots \ldots \ldots
\end{aligned}
$$

where $K^{\prime}$ and $K j$ are constants.

However, for the fluorescent lamp in which the mercury pressure is low and the electron density is not uniform in the discharge tube, it is difficult to describe exactly the disappearance of the electron.

So, we express approximately the disappearance of the electron as follows, considering to the third term of the electron density $n$.

$$
d n / d t=-\left(\mathrm{K} 2 n^{3}+\mathrm{K} 2 n^{2}+\mathrm{K} 3 n\right), .
$$

where $\mathrm{K} 1, \mathrm{~K} 2, \mathrm{~K} 3$ are constants.

It is assumed that the equivalent instantaneous conductance $g$ is proportional to the electron density $n,(g=i / v)$. From (10), the time rate of decrease term of the equivalent conductance $g$ is

$$
Q(g)=\left(D g^{3}+E g^{2}+F g\right), \ldots \ldots \ldots
$$

where $D, E, F$ are the constants.

From (7) is the increase term which consisted by three components of $A i^{2}, B i v, C v^{2}$. The same as (11) is the decrease term which is consisted by three components of $D g^{3}, E g^{2}$, and $F g$. Then, the combination of (7) and (11) gives 


$$
\frac{d g}{d t}=\left(A i^{2}+B i v+C v^{2}\right)-\left(D g^{3}+E g^{2}+F g\right) .
$$

Such as a differential equation of electron density was proposed by Francis ${ }^{1)}$, S. C. Peek ${ }^{2}$, and Nishioka ${ }^{3)}$, respectively. From (12) can be modified to give the model equations of electric circuit lamps. According to the postulation of Francis $^{1)}$, that the increase term and increase term of (12) can be combined to formulate some the model equations. These, there are 9 model equations with 2 model constants. 18 model equations with 3 model constants, 15 model equations with 4 model constants, 6 model equations with 5 model constants, and 1 model equations with 6 model constants.

All model equations may be very complicated because of the non linear and nonexplicit nature of the lamp circuit equations, therefore, some of these model equations become unsuitable. But we found the modern simulation techniques which are suitable to analyze these problem, which are used the simplex method to optimize the model constants.

\section{Determination of model equations}

In determination of model constants, it is important to use the model equations to analize the characteristics of fluorescent lamps. The process of determination of model constants was explaned in (5). Therefore, the same method we used for the suitable model equations, which are mainly to simulate the model equations on the high frequency operation.

The model constants are determined by the following processes;

(1) Measurement of the instantaneous values of the lamp voltage and the lamp current.

(2) Calculation of the instantaneous values of $g$ and $d g / d t$ by using the value (1).

(3) Determination of the model constants by the multiple regression method.

(4) Optimization of the model constants by the simplex method using the values obtained in (3) as the initial points in the simplex method.

(5) Optimization of the model constants by the simplex method using the values obtained (4) as the initial points for the next determinations of higher frequencies.
The error-rate $T_{\epsilon}$ is determined as the standard of estimation, that is the summation of errorrate of the lamp voltage $V_{\epsilon}$ and the error-rate of lamp current $I_{\epsilon}$.

$$
\begin{aligned}
\mathrm{EPS} & =T_{\epsilon}=V_{\epsilon}+I_{\epsilon} \\
& =\frac{\Sigma(v-\bar{v})^{2}}{\Sigma v^{2}}+\frac{\Sigma(i-\bar{i})^{2}}{\Sigma i^{2}}, \ldots
\end{aligned}
$$

where $v$ and $i$ are the instantaneous values of lamp voltage and lamp current obtained by the experimental, $\bar{v}$ and $\bar{i}$ are the instantaneous values of lamp voltage and lamp current obtained by the simulation. The process of simulation is shown in Fig. 1.

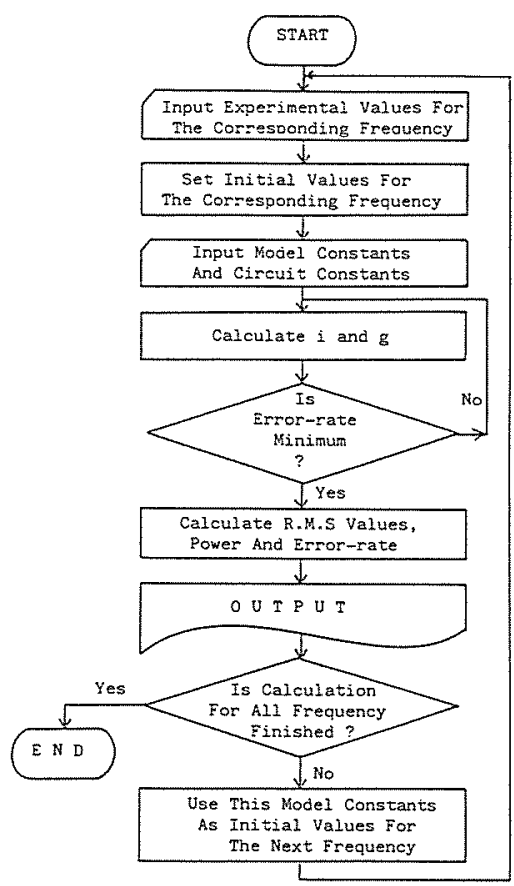

Fig. 1 Flow chart of simulation.

In the case of model equation (12), it is necessary to select the suitable model equations as follows;

For the model equations with 2 model constants are

$$
\begin{aligned}
& \left(\frac{d g}{d t}\right)_{21}=A_{21} i^{2}-E_{21} g^{2}, \ldots \ldots \ldots \\
& \left(\frac{d g}{d t}\right)_{22}=B_{22} i v-F_{22} g \ldots \ldots \ldots \ldots
\end{aligned}
$$

For the model equations with 3 model constants are

$$
\left(\frac{d g}{d t}\right)_{31}=A_{31} i^{2}+B_{31} i v-F_{31} g, \ldots
$$




$$
\begin{aligned}
& \left(\frac{d g}{d t}\right)_{32}=A_{32} i^{2}+C_{32} v^{2}-E_{32} g^{2}, \ldots \\
& \left(\frac{d g}{d t}\right)_{33}=A_{33} i^{2}-D_{33} g^{3}-E_{33} g^{2}, \ldots \\
& \left(\frac{d g}{d t}\right)_{34}=B_{34} i v+C_{34} v^{2}-F_{34} g, \ldots \\
& \left(\frac{d g}{d t}\right)_{35}=B_{35} i v-D_{35} g^{3}-F_{35} g, \ldots \\
& \left(\frac{d g}{d t}\right)_{36}=B_{36} i v-E_{36} g^{2}-F_{36} g . \ldots
\end{aligned}
$$

For the model equations with 4 model constants are

$$
\begin{aligned}
& \left(\frac{d g}{d t}\right)_{41}=A_{41} i^{2}+B_{41} i v+C_{41} v^{2}-F_{41} g, \\
& \ldots \ldots \ldots \ldots \ldots \ldots \ldots \ldots \ldots \ldots) \\
& \left(\frac{d g}{d t}\right)_{42}=A_{42} i^{2}+B_{42} i v-D_{42} g^{3}-E_{42} g^{2}, \\
& \text {................... (16b) } \\
& \left(\frac{d g}{d t}\right)_{43}=A_{43} i^{2}+B_{43} i v-D_{43} g^{3}-F_{43} g, \\
& \ldots \ldots \ldots \ldots \ldots \ldots \ldots(16 \mathrm{c}) \\
& \left(\frac{d g}{d t}\right)_{44}=A_{44} i^{2}+B_{44} i v-E_{44} g^{2}-F_{44} g, \\
& \ldots \ldots \ldots \ldots \ldots \ldots \ldots \ldots \ldots \ldots \ldots \ldots(16 \mathrm{~d}) \\
& \left(\frac{d g}{d t}\right)_{45}=A_{45} i^{2}+C_{45} v^{2}-D_{45} g^{3}-F_{45} g, \\
& \text {.................. (16e) } \\
& \left(\frac{d g}{d t}\right)_{46}=B_{46} i v+C_{46} v^{2}-D_{46} g^{3}-F_{46} g, \\
& \ldots \ldots \ldots \ldots \ldots \ldots \ldots(16 \mathrm{f}) \\
& \left(\frac{d g}{d t}\right)_{47}=B_{47} i v+C_{47} v^{2}-E_{47} g^{2}-F_{47} g, \\
& \ldots \ldots \ldots \ldots \ldots \ldots(16 \mathrm{~g}) \\
& \left(\frac{d g}{d t}\right)_{48}=B_{48} i v-D_{48} g^{3}-E_{48} g^{2}-F_{48} g .
\end{aligned}
$$

For the model equations with 5 model constants are

$$
\begin{aligned}
\left(\frac{d g}{d t}\right)_{51} & =A_{51} i^{2}+B_{51} i v+C_{51} v^{2}-D_{51} g^{3} \\
& -E_{51} g^{2}, \ldots \ldots \ldots \ldots \ldots \ldots(17 \mathrm{a}) \\
\left(\frac{d g}{d t}\right)_{52}= & A_{52} i^{2}+B_{52} i v+C_{52} v^{2}-D_{52} g^{3} \\
& -F_{52} g, \ldots \ldots \ldots \ldots \ldots(17 \mathrm{~b})
\end{aligned}
$$

$$
\begin{aligned}
\left(\frac{d g}{d t}\right)_{53}= & A_{53} i^{2}+B_{53} i v+C_{53} v^{2}-E_{53} g^{2} \\
& -F_{53} g, \ldots \ldots \ldots \ldots \ldots \ldots(17 \mathrm{c}) \ldots \ldots \ldots \ldots \ldots \ldots \ldots \ldots \\
\left(\frac{d g}{d t}\right)_{54} & =A_{54} i^{2}+B_{54} i v-D_{54} g^{3}-E_{54} g^{2} \\
& -F_{54} g, \ldots \ldots \ldots \ldots \ldots \ldots \ldots \\
\left(\frac{d g}{d t}\right)_{55} & =A_{55} i^{2}+C_{55} v^{2}-D_{55} g^{3}-E_{55} g^{2} \\
& -F_{55} g . \ldots \ldots \ldots \ldots
\end{aligned}
$$

For the model equations with 6 model constants is

$$
\begin{aligned}
\left(\frac{d g}{d t}\right)_{61} & =A_{61} i^{2}+B_{61} i v+C_{61} v^{2}-D_{61} g^{3} \\
& -E_{61} g^{2}-F_{61} g . \ldots \ldots \ldots(18)
\end{aligned}
$$

Table 1. Simulation results of model constants and error-rate of equation (15a).

\begin{tabular}{r|c|c|c|c}
\hline FRQ & \multicolumn{3}{|c|}{ Model constants } & \multirow{2}{*}{$\begin{array}{c}\text { Error-rate } \\
\text { EPS }=T_{\epsilon}\end{array}$} \\
\cline { 2 - 5 }$(\mathrm{HZ})$ & $\mathrm{A}$ & $\mathrm{B}$ & $\mathrm{F}$ & $0.4611 \mathrm{E}-2$ \\
60 & $0.7445 \mathrm{E}+1$ & $0.2373 \mathrm{E}+0$ & $0.3022 \mathrm{E}+4$ & 0.461 \\
100 & $0.4967 \mathrm{E}+1$ & $0.2330 \mathrm{E}+0$ & $0.2644 \mathrm{E}+4$ & $0.620 \mathrm{E}-2$ \\
200 & $0.6755 \mathrm{E}+1$ & $0.1639 \mathrm{E}+0$ & $0.1719 \mathrm{E}+4$ & $0.7244 \mathrm{E}-2$ \\
300 & $0.9228 \mathrm{E}+1$ & $0.1354 \mathrm{E}+0$ & $0.1492 \mathrm{E}+4$ & $0.6837 \mathrm{E}-2$ \\
700 & $0.5331 \mathrm{E}+2$ & $0.5961 \mathrm{E}-4$ & $0.1943 \mathrm{E}+4$ & $0.8236 \mathrm{E}-2$ \\
$1 \mathrm{~K}$ & $0.5940 \mathrm{E}+2$ & $0.3440 \mathrm{E}-4$ & $0.2150 \mathrm{E}+4$ & $0.9589 \mathrm{E}-2$ \\
$2 \mathrm{~K}$ & $0.6265 \mathrm{E}+2$ & $0.2688 \mathrm{E}-4$ & $0.1984 \mathrm{E}+4$ & $1.4150 \mathrm{E}-2$ \\
$3 \mathrm{~K}$ & $0.2802 \mathrm{E}+2$ & $0.6064 \mathrm{E}-4$ & $0.8044 \mathrm{E}+3$ & $1.3650 \mathrm{E}-2$ \\
$4 \mathrm{~K}$ & $0.2840 \mathrm{E}+2$ & $0.6405 \mathrm{E}-4$ & $0.7688 \mathrm{E}+3$ & $1.4750 \mathrm{E}-2$ \\
$5 \mathrm{~K}$ & $0.2847 \mathrm{E}+2$ & $0.6168 \mathrm{E}-4$ & $0.6976 \mathrm{E}+3$ & $1.7170 \mathrm{E}-1$ \\
\hline
\end{tabular}

In order to determine the model equations (14a) up to (18), we simulated all of these terms and evaluated model equations from the errorrate $\mathrm{T}_{\epsilon}$, and simulated the waveforms. The model constants of these model equations must be greater than zero, if not, the terms make no sense physically. By using data of the glow type fluorescent lamp of 40 watts (FL40). The suitable model equations have the same characteristics. Therefore, it is sufficiently to select the analysis results of equation (15a) as shown in Table 1. The characteristics of model constants and error-rate as function of frequencies are shown in Fig. 2. The lamp voltage wave, the lamp current wave, and the equivalent conductance wave for the frequencies $56 \mathrm{~Hz}, 1.8 \mathrm{kHz}$ and $3.9 \mathrm{kHz}$, respectively are shown in Fig. 3, where the solid line is the experimental wave and the dotted line is the simulation wave. 


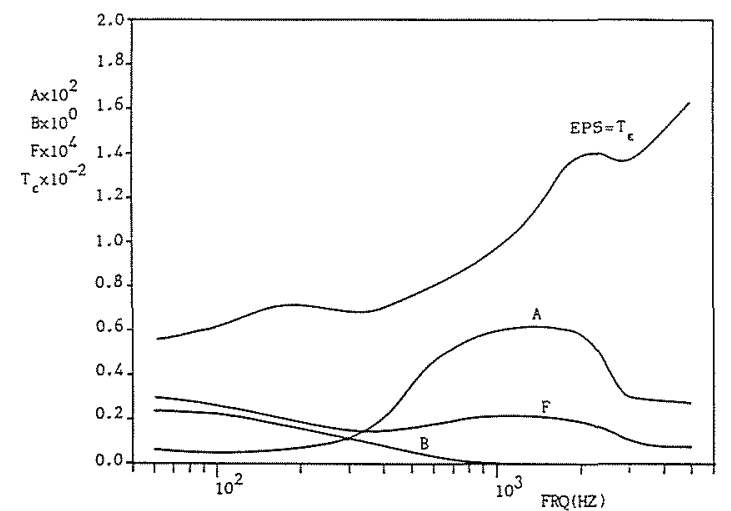

Fig. 2 Characteristics of model constants of equation (15a) us frequencies, when undelay time.
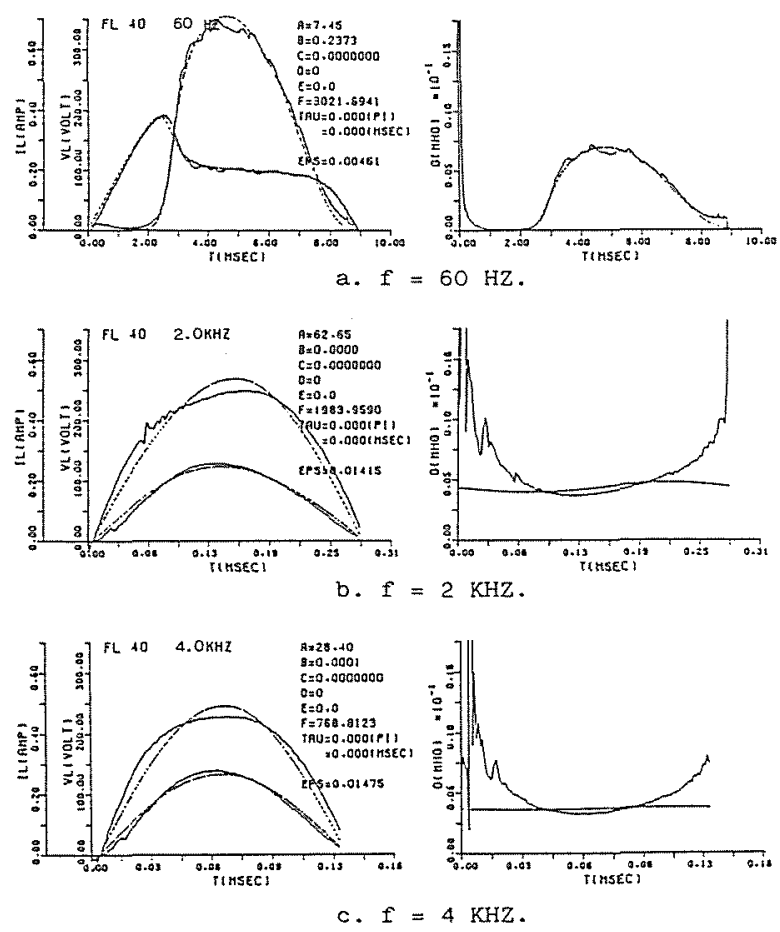

Fig. 3 Measurement and simulation results of lamp voltage, lamp current, and equivalent conductance of equation (15a) on undelay time.

a. $f=60 \mathrm{~Hz}, b . f=2 \mathrm{kHz}, c . f=4 \mathrm{kHz}$

\section{Improvement of model equations}

The model equations (14a) up to (18) on the high frequency operation can be improved to obtain the most suitable model equations. In the mercury lamps, the both recombination phenomenon and diffusion phenomenon for the decrease term of model equations are sufficiently and there are no problems, but in the fluorescent lamps the disappearance of electron in the positive column are only the diffusion phenome- non. Therefore, the problem is considered in the increase term.

If the frequency increases, the peak of the equivalent conductance wave changes. Therefore, it is necessary to consider the delay time. The model equations (14a) up to (18) are proposed by the delay time $\tau$, and we obtained the new model equations. All of the new model equations, we selected one of each type as follows;

For 2 model constants type gives

$$
\left(\frac{d g}{d t}\right)_{2}=\left[\frac{B_{2}}{g(t-\tau)} i^{2}(t-\tau)-F_{2} g(t), \ldots\right.
$$

For 3 model constants type gives

$$
\left(\frac{d g}{d t}\right)_{3}=\left[A_{3}+\frac{B_{3}}{g(t-\tau)}\right] i^{2}(t-\tau)-F_{3} g(t) .
$$

For 4 model constants type gives

$$
\begin{aligned}
\left(\frac{d g}{d t}\right)_{4}= & {\left[A_{4}+\frac{B_{4}}{g(t-\tau)}\right] i^{2}(t-\tau)-D_{4} g^{3}(t) } \\
& -F_{4} g(t) \ldots \ldots \ldots \ldots \ldots(21)
\end{aligned}
$$

For 5 model constants type gives

$$
\begin{aligned}
\left(\frac{d g}{d t}\right)_{5}= & {\left[A_{5}+\frac{B_{5}}{g(t-\tau)}+\frac{C_{5}}{g^{2}(t-\tau)}\right] i^{2}(t-\tau) } \\
& -D_{5} g^{3}(t)-F_{5} g(t) . \ldots \ldots(22)
\end{aligned}
$$

For 6 model constants type gives

$$
\begin{aligned}
\left(\frac{d g}{d t}\right)_{6}= & {\left[A_{6}+\frac{B_{6}}{g(t-\tau)}+\frac{C_{6}}{g^{2}(t-\tau)}\right] i^{2}(t-\tau) } \\
& -D_{6} g^{3}(t)-E_{6} g^{2}(t)-F_{6} g(t) \\
& \ldots \ldots \ldots \ldots \ldots \ldots \ldots \ldots \ldots \ldots
\end{aligned}
$$

There are difference between the model equations with undelay time and the model equations with delay time. The model equations with undelay time, if the frequency increase, the errorrate become higher, as shown in Table 1 and Fig. 2. From the determination results, the value of model constants are influence by the frequency. However, we selected one of them to represent the differential model equations.

The suitable model equations with delay time on the high frequency operation have the similar characteristics, and the error-rate is not much 
Table 2. Simulation results of model constants, delay time, and error-rate of equation (20).

\begin{tabular}{|c|c|c|c|c|c|}
\hline \multirow{2}{*}{$\begin{array}{l}\text { FRQ } \\
\text { (HZ) }\end{array}$} & \multicolumn{3}{|c|}{ Model constants } & \multirow{2}{*}{$\begin{array}{c}\text { Delay-time } \\
\text { TAU }=2 \pi \tau / T(\mathrm{rad})\end{array}$} & \multirow{2}{*}{$\begin{array}{c}\text { Error-rate } \\
\mathrm{EPS}=T_{\epsilon}\end{array}$} \\
\hline & $\mathrm{A}$ & B & $\mathrm{F}$ & & \\
\hline 60 & $0.7295 \mathrm{E}-1$ & $0.3410 E+0$ & $0.3577 \mathrm{E}+4$ & $\begin{array}{c}\times \pi \\
0.5744 \mathrm{E}-2\end{array}$ & $0.4065 \mathrm{E}-2$ \\
\hline 100 & $0.8085 \mathrm{E}-1$ & $0.2876 \mathrm{E}+0$ & $0.2908 \mathrm{E}+4$ & $0.5153 \mathrm{E}-2$ & $0.5747 \mathrm{E}-2$ \\
\hline 200 & $0.1243 \mathrm{E}+0$ & $0.1990 \mathrm{E}+0$ & $0.1757 E+4$ & $0.6219 \mathrm{E}-2$ & $0.7340 \mathrm{E}-2$ \\
\hline 300 & $0.3534 \mathrm{E}-2$ & $0.1907 \mathrm{E}+0$ & $0.1554 \mathrm{E}+4$ & $0.2064 \mathrm{E}-1$ & $0.6650 \mathrm{E}-2$ \\
\hline 700 & $0.7979 \mathrm{E}-4$ & $0.6586 \mathrm{E}+0$ & $0.3549 \mathrm{E}+4$ & $0.2009 \mathrm{E}+0$ & $0.2174 \mathrm{E}-2$ \\
\hline $1 K$ & $0.3957 \mathrm{E}-4$ & $0.8153 \mathrm{E}+0$ & $0.4501 \mathrm{E}+4$ & $0.2215 \mathrm{E}+0$ & $0.2020 \mathrm{E}-2$ \\
\hline $2 \mathrm{~K}$ & $0.8023 E-5$ & $0.1303 E+1$ & $0.7254 \mathrm{E}+4$ & $0.2681 \mathrm{E}+0$ & $0.3341 \mathrm{E}-2$ \\
\hline $3 \mathrm{~K}$ & $0.8864 \mathrm{E}-5$ & $0.1525 \mathrm{E}+1$ & $0.1005 \mathrm{E}+5$ & $0.2958 \mathrm{E}+0$ & $0.4311 \mathrm{E}-2$ \\
\hline $4 \mathrm{~K}$ & $0.8081 \mathrm{E}-5$ & $0.2072 \mathrm{E}+1$ & $0.1386 \mathrm{E}+5$ & $0.2902 \mathrm{E}+0$ & $0.4819 \mathrm{E}-2$ \\
\hline $5 \mathrm{~K}$ & $0.4345 \mathrm{E}-5$ & $0.2507 \mathrm{E}+1$ & $0.1716 \mathrm{E}+5$ & $0.2496 \mathrm{E}+0$ & $0.7593 \mathrm{E}-2$ \\
\hline
\end{tabular}

change. Therefore, it is sufficiently to perform the calculation results of equation (20) of 3 model constants with delay time. Then, the optimization result of this model equation is shown in Table 2 and is illustrated in Fig. 4 . The characteristics of the lamp voltage, the lamp

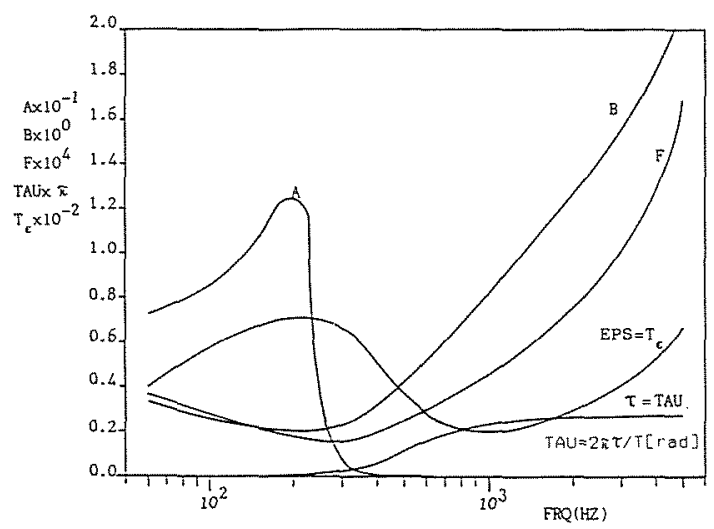

Fig. 4 Characteristics of model constants of equation (20) us frequencies, when delay time.

current, and equivalent conductance for the high frequency operation are shown in Fig. 5, where the solid line is the experimental wave and the dotted line is the simulation wave.

The lamp characteristics, the circuit components, and the application of high frequency fluorescent lighting have been explained in (6), (7), respectively. Therefore, the nonlinear, characteristics results in waveform distortion and operation with a sine wave current will give a lamp voltage having approximately a square wave shape. For this reason, most of the discharge lamp circuit are operated in a.c. take a current having a wave shape which is nonsinusoidal wave, that is the input current contains a proportion of harmonics. Because of the waveform distortion, the design and evaluation of the lamp
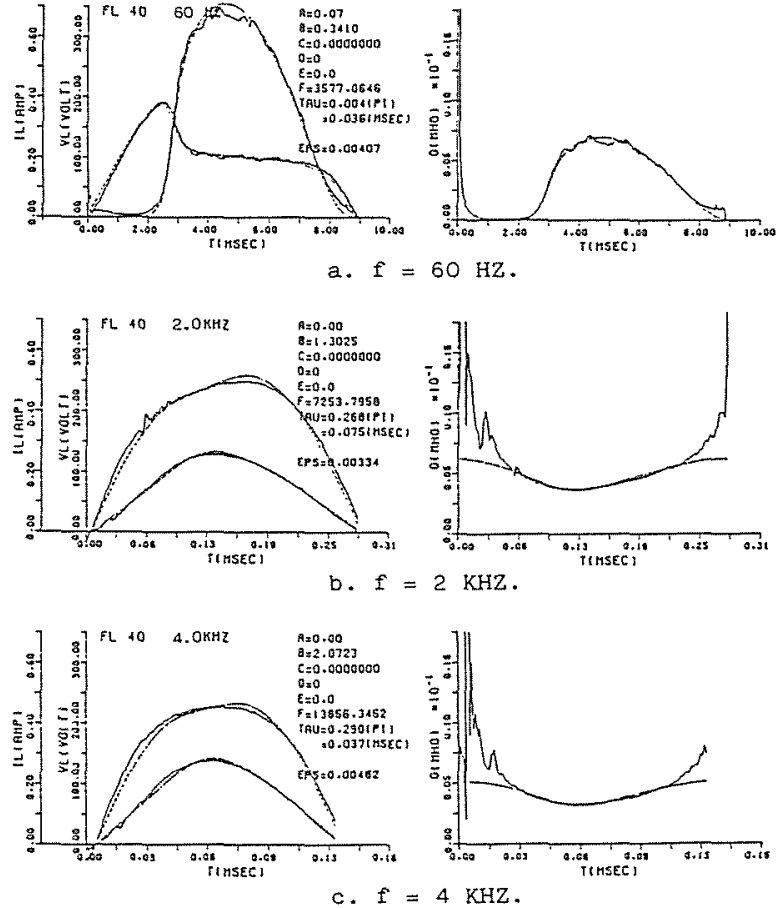

Fig. 5 Measurement and simulation results of lamp voltage, lamp current, and equivalent conductance of equation (20) on delay time.

a. $f=60 \mathrm{~Hz}, b . f=2 \mathrm{kHz}, c . f=4 \mathrm{kHz}$

circuit is complex, and simple equivalent circuit design of the fluorescent lamp is needed partly theoretical and partly empirical of the model equation.

At the high frequency operation, the ionization state of the lamp can no longer follow the rapid changes of lamp current during each cycle and this result is near the constant plasma density and the constant effective resistance throughout the cycle. The dynamic lamp voltage-current characteristics is shown in Fig. 6, where a characteristic of a suitable model equation. There- 

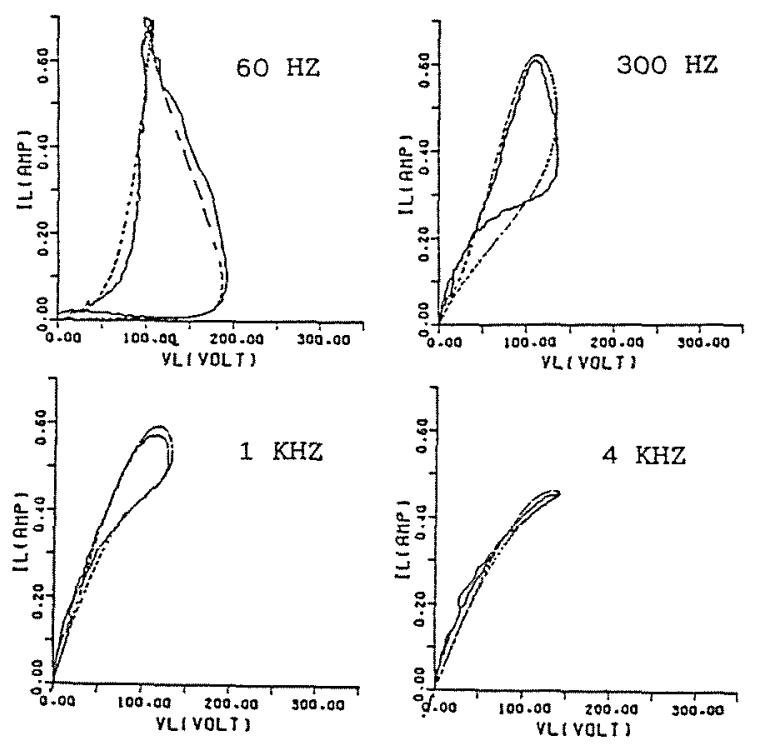

Fig. 6 Dynamics volt-ampere characteristics of fluorescent lamp operated on various frequencies.

fore, at the higher frequencies, the form of characteristic become linear.

\section{Conclusion}

The main purpose of this paper is to determine the corresponding model equations of fluorescent lamp characteristics, especially on the high frequency operation. The model equations for the low pressure discharge lamps on the rated current and the resistance ballast circuit are expressed precisely. There are some suitable model equations have been selected to provide the most accurate determination. The suitable model equations are used for the commercial frequency $60 \mathrm{~Hz}$, but it is very suitable also for the high frequency operation. The model equations were improved to obtain the most accurate determination by considering the increase term of each model equation with delay time. The optimization of suitable model equations by the simplex method are necessary to minimize the error-rate between the experimental waveform and the simulation waveform. Therefore, the reliable model constants of each model equation are used to obtain the high precise of the suitable model equations.

The views of mention of the fluorescent lamp on the high frequency operation are advantaged to make the ballast much smaller, the watt losses will be lower, the lamp efficiency will be higher, and the luminous riple will be very slight. Practically, that the fluorescent lamps can be used for this purpose, because there is no need to correct for the current distortion, and the current wave on the high frequency become sine wave. Therefore, in view of the model equations of fluorescent lamps there are no problem in using for the high frequency, since the suitable model equations can be used for the determination of model constants and the electrical characteristics.

\section{References}

(1) Francis, V. J.: "Fundamental of Discharge Tube Circuit," John Wiley \& Sons, Inc., New York, N.Y., 1948.

(2) Peak, S. C. and Spencer, D. E.: "A Differential Equation for the Fluorescent Lamp," Illuminating Engineering (North America), 63, - 4 April (1968) 157.

(3) Nishioka, K. and Morimoto, O.: Joint Conv. Rec. of Four Inst. of Elec. Eng., Japan (1970) 806 (in Japanese).

(4) Masumi, K, and Bo, H.: "On Mathematical Model for Equivalent Conductance of Discharge Lamps," Journal of the Illuminating Engineering Institute of Japan, 57 - 6, June (1973) 342 (in Japanese).

(5) Tola, M. and Bō, H.: "Model Equations of Flurrescent Lamps," Memo. Grad. School Sci \& Technol., Kobe Univ., 2-A; 1-24, (1984).

(6) Henderson, S. T., et. al., "Lamps and Lighting," Second Edition, Edward Arnold, 1972, p.315p.319.

(7) Campbell, J. H., Schultz, H. E., Kershaw, D. D., "Characteristics and Applications of HighFrequency Fluorescent Lighting," Illuminating Engineering, February 1953, p.95-p.103.

Received 4, Mar. 1985; Division 2 July. 1986 